\title{
Velhos problemas? Público, acervos, leitura e bibliotecários em cenas da história da biblioteca pública
}

\author{
Ana Maria de Oliveira Galvão \\ Doutora em Educação. Professora Associada da \\ Faculdade de Educação da UFMG.
}

http://dx.doi.org/10.1590/1981-5344/2277

O artigo tem como objetivo discutir quatro grandes preocupações que têm sido permanentes na história das bibliotecas públicas: o público e o acesso; a constituição dos acervos; o controle sobre os modos de ler; e o papel do profissional responsável por essa instituição. Essas quatro preocupações são discutidas a partir da reconstrução de cenas que as expressaram em diferentes momentos históricos, no Brasil e em outros países. Constatamos que: há uma tensão, ao longo da história, entre atender às demandas do público leitor e as leituras consideradas benéficas pelos bibliotecários e professores na constituição dos acervos das bibliotecas; o par leitura e instrução-educação tem se sobreposto ao par leitura e lazer-diversão na constituição dos acervos; há uma tentativa de controle também dos modos de ler na biblioteca; gradativamente, os papéis atribuídos aos bibliotecários têm se complexificado - de conservador a mediador da leitura.

Palavras-chave: Biblioteca pública. História. Leitura.

\section{Old problems? Public collections, librarians, and reading scenes in the history of the public library}

This article aims to discuss four major concerns that have been standing in the history of public libraries: the public and the access; the creation of collections; the control over the ways of reading; the role of the professional in charge of the institution. We discussed these four concerns using the reconstruction of scenes that expressed them in different historical moments, in Brazil 
and in other countries. We found that: there is a tension, throughout history, between the demands of the readers and the readings considered beneficial by librarians and teachers in the constitution of the collections; reading has been associated with instruction and education more than with leisure and fun, in the constitution of collections; there is also an attempt to control the ways of reading in the library; gradually, the roles of the librarian have complexified - from a conservative to a reading mediator.

Keywords: Public library. History. Reading. History.

Recebido em 20.11.2014 Aceito em 24.11.2014

\section{Introdução}

Uma prática, um lugar e uma escrita. Michel de Certeau (1982) assim define os elementos que constituem a operação historiográfica. Ao dizer do lugar de produção, o autor refere-se, fundamentalmente, ao lugar institucional do pesquisador - e, por conseguinte, às relações de poder dele constitutivas - e também ao lugar do presente, tempo ocupado, inexoravelmente, pelo historiador. Essas duas dimensões, mesmo que não tenhamos delas consciência, nos faz optar por certas histórias, e não por outras. O fato de ser pesquisadora dos campos da História da Educação e da História da Cultura Escrita tem feito com que eu estude a história das bibliotecas a partir de um olhar muito específico, e isso, certamente, tem consequências nas abordagens escolhidas para tratar o tema neste artigo. O presente também inquieta e interroga, e coloca-nos diante de realidades que nos fazem selecionar, do passado, aquilo que parece mais interessante para compreender uma biblioteca em processo de reconfiguração, diante de um novo contexto social, em que novas mídias, novos gêneros literários e novos públicos são onipresentes.

Foi, então, a partir desse duplo olhar construído pelo lugar de produção em que me encontro - institucional e do tempo presente - que, nos últimos anos, ao realizar estudos e pesquisas e, por meio deles, percorrer a história das bibliotecas, tanto no Brasil, quanto em outros países do mundo ocidental, pude constatar que, pelo menos, quatro grandes preocupações têm-se revelado constantes na história das bibliotecas públicas: o público e o acesso; a constituição dos acervos; a necessidade do controle sobre os modos de ler; e o papel do profissional responsável por essa instituição.

Neste artigo, abordarei essas quatro preocupações, por meio da discussão de cenas que as expressaram, em diferentes momentos históricos, tanto no Brasil, quanto em outros países. São cenas (re)construídas a partir estudos que realizei mas também, e principalmente, a partir de outros estudos. 


\section{O público da biblioteca e o acesso a essa instituição}

Cena 1

Estamos na famosa biblioteca de Nínive, no século VI a.C. A sua única porta dá para o interior do edifício, para o lugar onde viviam os grandes sacerdotes. Não havia, portanto, saída para o exterior. ${ }^{1}$

\section{Cena 2}

Estamos agora em um mosteiro medieval. A biblioteca funciona como um depósito de livros, mas também como um lugar que os produz. Em uma época anterior à invenção da imprensa, monges copiam, laboriosamente, manuscritos. Alguns deles não conseguem ler, mas são capazes de copiar. Somente os clérigos podem consultar esse espaço sagrado. ${ }^{2}$

\section{Cena 3}

França, 1860. Diante da constatação de que os manuais didáticos e outros materiais escolares estavam se deteriorando, o Ministro da Instrução Pública e dos Cultos determina que cada prefeito instale, em todas as escolas dos seus municípios, uma pequena biblioteca-armário, destinada à conservação desses materiais e à ampliação das possibilidades de leitura dos alunos e de seus familiares. ${ }^{3}$

\section{Cena 4}

Bibliotecários fazem pesquisas para levantar os livros preferidos dos frequentadores de uma biblioteca de periferia de uma grande cidade norte-americana nos anos 1930. A biblioteca é frequentada, principalmente, por famílias de classes trabalhadoras, de imigrantes e de afro-americanos ${ }^{4}$.

\section{Cena 5}

1949. Inaugurada a Biblioteca Pública de Casa Amarela, Recife, Pernambuco. Zé Moreno, morador do bairro, um ano de escola e leitor voraz de livros de detetives, vê o prédio sendo erguido mas, para ele, aquilo era um "bicho brabo". ${ }^{5}$

\section{Cena 6}

2013. Crianças e jovens se movimentam em uma tarde de sábado na biblioteca pública de uma pequena cidade do Norte dos Estados Unidos. A biblioteca se impõe na cena urbana. É lugar de encontro, de navegar na internet, de fazer o empréstimo de um livro pertencente aos consagrados cânones literários, do último best-seller ou de um jogo de computador.

\footnotetext{
${ }^{1}$ Cena reconstruída a partir de Martins (2002).

${ }^{2}$ Cena reconstruída a partir de Petrucci (1999).

${ }^{3}$ Cena reconstruída a partir de Hébrard (2009).

${ }^{4}$ Cena reconstruída a partir de Galvão (2013).

${ }^{5}$ Cena reconstruída a partir de Galvão (2000).
} 
Como mostram as cenas 1 e 2, até a invenção da biblioteca moderna, a questão do público a ser por ela atendido não se colocava como questão. Como mostra, entre outros, Petrucci (1999), até a Renascença, as bibliotecas eram uma instituição, dos pontos de vista físico e conceitual, própria e exclusiva da cultura religiosa, e um lugar destinado à conservação e repetição da textualidade escrita em língua latina. Não estavam, portanto, à disposição dos profanos, pois eram consideradas organismos mais ou menos sagrados, a que tinham acesso apenas os que faziam parte de uma certa 'ordem', de um 'corpo' igualmente religioso ou sagrado", pois o "livro, a palavra escrita, eram o mistério, o elemento carregado de poderes maléficos para os nãoiniciados: cumpria manuseá-los com os conhecimentos exorcismatórios indispensáveis". (MARTINS, 2002, p. 71). Eram, portanto, prioritariamente, um depósito de livros e, nas palavras de Martins, mais o lugar onde se escondia o livro do que o lugar de onde se procurava "fazêlo circular ou perpetuá-lo". (p. 71).

Como expressa a cena 3,0 acesso coloca-se como questão principalmente a partir do século XIX, quando duas necessidades se impõem socialmente: é preciso conservar os livros e os documentos e, ao mesmo tempo, difundir "boas leituras" para um novo público leitor. Na França, em 1860, o Ministro da Instrução Pública e dos Cultos, Gustave Rouland, em um contexto de universalização da escola pública, acredita que, para instruir "é necessário quadros-negros, mesas, penas, papel, mas também livros" (HÉBRARD, 2009, p. 7). Na verdade, o ministro coloca em funcionamento a primeira rede de bibliotecas populares: "o armário-biblioteca não tem apenas a função de preservar os instrumentos do professor, mas foi pensado, de início, como o núcleo de uma instituição de leitura destinada prioritariamente às populações pouco familiarizadas ou não familiarizadas com o impresso, e deveria, depois, se impor em cada um dos 36.000 municípios do território nacional". (HÉBRARD, 2009, p. 9). O desejo de propagar a cultura do livro em camadas sociais não letradas é, segundo Hébrard (2009), típico do século XIX. Está, na análise do autor, vinculado menos à concepção Iluminista e mais à preocupação do enquadramento das massas rurais e populares e ao desenvolvimento das ações pastorais católicas. As bibliotecas representam, nesse sentido, um dos aspectos desse empreendimento de "aculturação pela escrita que nasce nos primeiros anos da Restauração, cujos iniciadores são, com o mesmo zelo, a Igreja (...) e os grupos de pressão liberais". (HÉBRARD, 2009 , p. 10). Por isso, essas pequenas bibliotecas escolares terão a dupla finalidade de serem tanto bibliotecas de sala quanto bibliotecas de empréstimos destinadas aos familiares dos alunos. (HÉBRARD, 2009, p. 17). É certo que, anteriormente a esse período, já existiam, no caso francês, instituições que realizavam o empréstimo de livros a um público não especializado, mas elas estavam vinculadas, na maioria das vezes, a associações culturais e políticas, às igrejas, às fábricas. A iniciativa do armário biblioteca, além de ser pública, atingia todo o país, na medida em que usava a rede de escolas. 
O sistema de bibliotecas públicas nos Estados Unidos, por sua vez, constituiu-se de modo bem diferente, desvinculado da escola. Em meados do século XIX, já havia uma ampla rede de bibliotecas em todos os recantos do país, mesmo nas pequenas cidades e nas periferias das grandes cidades. A fundação das bibliotecas era patrocinada tanto por verbas públicas quanto privadas e deve ser analisada em um contexto mais amplo em que vários esforços eram realizados para prevenir o envolvimento dos jovens em diversões "mundanas", para auxiliar o estabelecimento dos imigrantes nas pequenas cidades, e para difundir a moral protestante, por meio de uma literatura edificante (PAWLEY, 1998). Como mostram as cenas 4 e 6 , no século $X X$, assim como nesse início do XXI, a biblioteca pública tem grande presença na cena urbana daquele país, e atende a públicos diversos. Estudos como os de Graff (1995), Brandt (2001) e Galvão (2013) mostram que a biblioteca pública e as bibliotecas de associações desempenharam o papel de um importante agente de letramento no caso norte-americano, tanto para as famílias de classe média, quanto para as famílias de camadas populares, de imigrantes e de afro-americanos. Ao lado da escola, a biblioteca representava, muitas vezes, a única possibilidade de acesso desses grupos sociais à palavra escrita, mas também a exposições, palestras e cursos (TINSLEY; KAESTLE, 1991, p. 238). É interessante observar que, desde 0 início do século $X X$, havia uma preocupação, entre os bibliotecários, em tornar a biblioteca atraente para os diferentes tipos de público. Uma das pesquisas realizadas no país na década de 30 revelava que o que as pessoas realmente liam era resultado não apenas dos seus interesses, mas também - e talvez principalmente - da acessibilidade e da legibilidade dos materiais (DAMON-MOORE; KAESTLE, 1991, p. 182).

No Brasil, no século XIX, havia, por outro lado, pouquíssimas bibliotecas públicas. As bibliotecas particulares, que se revestiam, é verdade, de um caráter por vezes público, e pertencentes, sobretudo, aos clérigos, predominaram na colônia (MORAES, 2006; VILLALTA, 1997). Com a vinda da família real, veio também a primeira Biblioteca Nacional (SCHWARCZ, 2002) e, a partir de então, bibliotecas públicas foram fundadas nas vilas e cidades mais populosas. A ideia dessas bibliotecas, patrocinadas pelas elites letradas masculinas, era a de difundir as letras e a civilização entre a população (MORAIS, 2002; PERES, 2002). Essas instituições faziam parte de um conjunto de obras - como hospitais, asilos e orfanatos - através das quais os homens "ilustrados" poderiam exercer a filantropia. As bibliotecas, ao lado das sociedades literárias e dos jornais, serviam, como em outros países do mundo, para aculturar a massa iletrada que, no Brasil, entretanto, representava cerca de $80 \%$ da população nas décadas finais dos oitocentos. A expansão das bibliotecas públicas tem-se dado, então, no caso brasileiro, de modo bastante lento, ao longo do século XX (e XXI). Em 1935, por exemplo, Belo Horizonte tinha apenas uma biblioteca pública (IBGE, 1957).

Mesmo as bibliotecas escolares, no Brasil, somente começaram a ser fundadas, de modo mais amplo, com a criação dos grupos escolares, entre o final do século XIX e o início do século XX. A consolidação veio alguns 
anos mais tarde, com o advento da Escola Nova, que colocou essas instituições - tanto para os alunos quanto para os futuros professores -, ao lado do museu escolar, do cinema educativo e do laboratório, como fundamentais para dar um caráter mais científico à educação. No ano já citado de 1935, Belo Horizonte, além da biblioteca pública municipal, contava com 47 bibliotecas em instituições de ensino primário e secundário, 12 em instituições de ensino profissional e 9 em instituições superiores de ensino, totalizando 68 bibliotecas distribuídas entre instituições públicas e privadas de ensino (IBGE, 1957).

Além de muito rarefeitas nas cidades (e ausentes nas zonas rurais), as bibliotecas públicas eram vistas, muitas vezes, como estranhas ao universo dos moradores pouco familiarizados com a cultura escrita. Como mostra a cena 5, nem sempre esses equipamentos culturais, quando ocupavam o espaço público, eram reconhecidos pelas pessoas a que supostamente se destinavam, mesmo com o processo de sua expansão pelos bairros de periferia ${ }^{6}$. Em Pernambuco, apesar das campanhas realizadas nos anos 40 e 50 a favor de sua popularização ${ }^{7}$, segundo Zé Moreno, que se lembra da implantação da biblioteca pública de Casa Amarela, ocorrida em 1949, o "povo" não tinha o hábito de frequentá-la nem parecia saber quais eram as suas funções: Aquilo ali era mata, quando eu cheguei pra lá. (...) Depois foram desmatando, fizeram aquilo na década de... (...) fizeram aquela biblioteca. Eu até isso eu nem sabia o que significava, o significado de biblioteca, pra mim era um bicho brabo (risos). (GALVÃO, 2001).

O medo e a ideia de não pertencimento não eram exclusivos de Zé Moreno. Nos Estados Unidos, também em meados do século XX, Vera, de família de classe operária, descobriu, quando estava no ensino fundamental, uma biblioteca pública a poucos quarteirões da sua casa, mas o edifício imponente a intimidava e ela tinha medo de entrar. Somente superou seus temores com a ajuda de uma amiga, e pode, então, desfrutar daquela "mesa de livros", estantes cheias do que queria ler e daquilo de que nunca tinha ouvido falar. (TINSLEY, KAESTLE, 1991, p. 240).

Também as bibliotecas escolares têm sido associadas, na memória de muitas gerações, ao medo, pois foram muito usadas como lugar de castigo. Uma ex-aluna que frequentou o Instituto de Educação do Rio de

\footnotetext{
${ }^{6}$ Não nos deteremos sobre o tema aqui, mas a expansão das bibliotecas deu-se também, em meados do século $\mathrm{XX}$, por meio de projetos como ônibus-bibliotecas, tanto na França, quanto nos Estados Unidos como no Brasil. Principalmente voltados para a zona rural, tratava-se agora, como afirmam Chartier e Hébrard (1995), "de oferecer livros aos supostos leitores, em lugar de lamentar-se sobre seu pequeno apetite para a leitura ou sobre sua falta de gosto". (p. 187).

7 O trabalho de Gilda Verri (1996) investiga a implantação de bibliotecas em bairros de grande concentração populacional do Recife - Encruzilhada, Casa Amarela, Afogados e Santo Amaro - , a partir dos anos 40, como parte de um projeto mais amplo de popularização da cultura, promovido pela prefeitura, que incluía também a criação de uma discoteca (com auditório, cabines individuais, coleção de livros sobre música, sala de leitura), um posto de empréstimos no centro da cidade e um ônibus-biblioteca. A Biblioteca Pública de Casa Amarela, por exemplo, criada em 1949, dispunha de oito mil volumes, de salas de leitura para adultos e crianças, além de auditório. O ônibus-biblioteca, criado em 1954, tinha capacidade para 1.300 livros e percorria, em horários diurnos e noturnos, quase todos os bairros populares e de classe média do Recife.
} 
Janeiro na década de 30 , deu o seguinte depoimento à pesquisa de Vidal (2000):

Nós tínhamos aula de biblioteca. Era obrigatório. Tínhamos aula de pesquisa de biblioteca, pelo menos uma hora por semana. (...) Ou então, íamos quando não tínhamos aula. Nós não ficávamos na sala de aula. Éramos encaminhadas para a biblioteca (...) A gente era muito levada. Depois, à medida que o número de alunos do Instituto de Educação foi aumentando, eles já começaram a não empurrar mais os alunos como foi a primeira turma. (apud VIDAL, 2000, p. 11).

\section{O controle do acervo}

\section{Cena 1}

Brasil, 1594. Um representante do Santo Ofício em Pernambuco coleta o depoimento de um denunciante. Gaspar Rodrigues, cristão novo natural da cidade do Porto, cerca de 40 anos, lavrador, solteiro, afirma que, há cerca de cinco anos, havia visitado Bento Teixeira, "mestre de insinar moços", em sua casa, "hum dia não lhe lembra qual nem a que oras o achou lendo per hum livro e the perguntou que livro era e elle the respondeo que era Diana, e elle denunciante o repreende o logo que pois sabia que era defeso". Bento, então, havia lhe respondido que "era verdade mas que elle o queimaria". O denunciante disse também que, há cerca de três ou quatro anos, havia visto Jorge Fernandes "ter hum livro de sortes no qual se lançavão tres dados e por certo pontos e letras vião a quantas folhas avião de ir buscar o que queriam saber e lhe vio fazer per muitas vezes as dittas sortes pera saber o que cada hum lhe perguntavão e fazia as dittas sortes perante muitas pessoas", que pareciam ignorar que esse livro também era proibido. (PRIMEIRA, 1984, p. 170-171).

\section{Cena 2}

França, 1860. O Ministro da Instrução e dos Cultos envia uma circular aos prefeitos indicando que tipo de acervo deveria constar nas bibliotecas armários para atender aos familiares dos alunos: "Dotar as populações trabalhadoras de um acervo de obras interessantes e úteis é uma necessidade que, a cada dia, faz-se sentir mais seriamente". (HÉBRARD, 2009, p. 9).

\section{Cena 3}

Ouro Preto, Minas Gerais, 1870. O Diretor de Instrução Pública envia um ofício ao Presidente da Província, informando sobre as condições materiais da biblioteca pública da cidade. Além de discorrer sobre a necessidade de tomar providências para evitar o extravio dos livros, afirma que, embora a biblioteca se situasse em um lugar central e, por isso, "ao alcance de todos que se queirão das á leitura dos livros alli existentes", o número de leitores era "bem deminuto". Para ele, um dos motivos para que isso ocorresse era a "composição" da biblioteca, "cujas 
obras são pela maior parte tratadas de sciencias sociaes e juridicas, q não podem attrahir um grande numero de leitores" ${ }^{8}$.

\section{Cena 4}

Rio de Janeiro, década de 1930. Biblioteca do Instituto de Educação. Burlando a vigilância da "encarregada", as alunas abriam o livro indicado por ela e colocavam o romance que realmente gostariam de ler - levado de casa dentro da bolsa - no meio. A um só tempo, correspondiam aos seus desejos mais íntimos de leitoras ávidas por percorrer as páginas da narrativa e saber os destinos reservados à mocinha, ao mocinho e à traidora, e às expectativas da escola e da bibliotecária. ${ }^{9}$

\section{Cena 5}

Natal. 1960. A criação de bibliotecas populares é uma das prioridades da Campanha De Pé no Chão também se Aprende a Ler. Compostas de doações de livros, priorizavam, em seu acervo, obras que pudessem contribuir para a conscientização do povo e para a transformação social. Os empréstimos, por mês, eram da ordem de 2.500 exemplares $^{10}$.

A ideia de que é preciso controlar o acervo das bibliotecas é mais uma constante na história da instituição. A discussão em torno do que deve e do que não deve compô-lo é permanente; o que muda, nessa história, é a ênfase em que tipo de material deve nele constar. Em quase todos os períodos, o destaque recai sobre os materiais que provoquem leituras edificantes e instrutivas. No século $X X$, mais um componente é adicionado a esse núcleo básico: a ideia de que a biblioteca também deve ser uma fonte de informação. Mas, o par mais constante na história é entre leitura e instrução-educação. O par menos constante, por outro lado, é entre leitura e lazer-diversão. A associação leitura-instrução parece impregnada, no decorrer dos séculos, nas mentalidades dos professores e dos bibliotecários, como se pode ver na Cena 2.

Embutida na escolha do acervo, estava a ideia de que era preciso, por um lado, impedir as más leituras (e é importante destacar que a noção do que é má leitura muda historicamente) e, por outro, mudar os gosto dos leitores, principalmente dos neo-leitores, pertencentes às camadas populares, a grupos como imigrantes, negros, mulheres, crianças. Para Jean-Jacques Darmon (1972), historiador citado por Hébrard (2009), a biblioteca escolar à française:

Faz parte de um conjunto de instituições de aculturação, preocupadas tanto com a incitação à leitura quanto com a censura. A fiscalização da colportagem, as coleções de livros editadas pelas associações filantrópicas, os cursos ou as

\footnotetext{
${ }^{8}$ Cena reconstruída a partir de Minas Gerais, 1870. Documento cedido por Raquel Menezes Pacheco, a quem agradeço.

${ }^{9}$ Cena reconstruída a partir de Vidal (2000).

${ }^{10}$ Cena reconstruída a partir de Costa e Germano (2002).
} 
leituras noturnas são, ao lado das bibliotecas escolares, igualmente, meios para transformar os gostos desses novos leitores produzidos pelo progresso da alfabetização. (HÉBRARD, 2009, p. 20).

Nessa direção, é recorrente a preocupação daqueles que estavam à frente da administração da instrução pública em fornecer livros úteis, que fossem capazes de fornecer lições morais e incitar o amor ao trabalho.

Se algumas obras eram consideradas úteis e instrutivas, outras aparecem como vilãs em muitos períodos da história. No século XIX e no início do século $X X$, por exemplo, muitas vezes o jornal foi considerado uma influência nefasta. Em meados do século $X X$, os novos inimigos das boas leituras eram o cinema, o rádio e a televisão. Atualmente, para alguns, é a internet. Os romances, principalmente para as mulheres, eram considerados perigosos, pois incitavam a imaginação sem freios e poderiam levá-las ao mundo dos devaneios e das frivolididades. Mesmo assim, e apesar do controle dos acervos, esses materiais eram lidos, como mostra a cena 3. As bibliotecas das escolas normais no Brasil priorizavam as leituras profissionais, e tinham um acervo reduzido de obras de literatura (VIDAL, 2000, p. 13). Mas as jovens queriam ler e conversar sobre o último romance.

Em virtude desse tipo de situação, as escolhas em torno do acervo geraram críticas tanto para os contemporâneos quanto para os que, posteriormente, fizeram as histórias das bibliotecas. A cena 3 mostra a crítica dos contemporâneos: o acervo da biblioteca de Ouro Preto parecia muito especializado para atrair leitores. Para Jean Hassenforder, o historiador dos anos 60 citado por Hébrard (2009), as primeiras bibliotecas escolares e públicas do século XIX não foram bem sucedidas porque além de gerenciadas por professores - que não possuíam nem o gosto nem a competência necessários para cumprir essa delicada e importante tarefa -, apresentavam problemas em seus acervos. Para ele, os acervos eram muito limitados e insuficientes para manter o interesse dos possíveis leitores por muito tempo. Além disso, os livros que o compunham eram deliberadamente muito didáticos $\mathrm{e}$, desse modo, entediantes, incapazes de provocar o prazer em ler.

Na França, essa tensão era permanente: como, ao mesmo tempo, proporcionar leituras "saudáveis" e atrair leitores? Por isso, o modelo anglo-saxão inquietava os franceses, pois, em países como a GrãBretanha e os EUA, a história era diferente. O espírito pragmático prevalecia. Não havia a ideia de que a biblioteca era um espaço quase sagrado. Os primeiros estudos sobre hábitos de leitura realizados nos Estados Unidos no início do século XX foram conduzidos por bibliotecários e eles buscavam entender quais eram os gêneros mais populares entre os leitores. Se os romances eram os preferidos, eles deveriam ser prioridade na aquisição. A preocupação dos bibliotecários era a de aumentar a frequência à biblioteca e, para isso, era preciso atender aos seus 
principais interessados: os leitores (DAMON-MOORE; KAESTLE, 1991, p. 180).

Essa relativização do controle do acervo tem impactos, ao longo do século $X X$, em vários outros países. No caso francês, por exemplo, na década de 1930, embora se observe a pregnância do discurso em torno da necessidade de proporcionar leituras "sadias", acrescenta-se a ideia de que essas leituras devem ser, também, divertidas. Nos anos 60, a preocupação já passa a ser em torno daqueles que não liam, nem mesmo as consideradas más leituras - como os romances de produção industrial, os jornais sensacionalistas ou as revistas de grande tiragem. O verbo ler passa a ser empregado de maneira intransitiva: é preciso ler, não importa o quê (CHARTIER; HÉBRARD, 1995).

Evidentemente, a tentativa de controle da leitura e do material que se lê não é exclusiva das bibliotecas. A história do Brasil está repleta de exemplos que expressam essa afirmação. No período colonial, os jesuítas buscavam evitar que os alunos lessem obras obscenas ou heréticas (MORAES, 2006). A cena 1 também nos mostra a preocupação da Igreja com os livros que poderiam ser fonte do pecado e da heresia: o livro Diana, citado na denunciação ao Santo Ofício, de autoria de Jorge de Montemor, foi proibido pelas autoridades religiosas porque seu autor era considerado um crítico de regras morais e de instituições como o casamento (SANTOS, 2007). No Estado Novo e na Ditadura Militar, temos vários estudos (ver, por exemplo, CARNEIRO, 2002) que mostram a forte censura e o recolhimento de livros considerado ofensivos aos regimes, à moral e os bons costumes; nesses períodos, também observamos a criação de órgão de controle, como o Instituto Nacional do Livro, em 1937, e a Comissão do Livro Técnico e do Livro Didático (COLTED), em 1966, que buscavam centralizar a decisão sobre a distribuição de livros nas escolas e nas bibliotecas.

Mas é na biblioteca que a ideia do controle do que deve ser lido independentemente das intenções de quem o faz, como mostra a cena 5 , adquire maior visibilidade. Como afirmam Chartier e Hébrard (1995):

Quaisquer que sejam as intenções que presidiram ao seu nascimento, a biblioteca é um dispositivo evidente de controle das leituras populares; controle conservador, reformista ou revolucionário, conforme o caso, controle privado ou público, conforme o Estado esteja ou não presente, mas sempre um controle daqueles que ainda não sabem ler bem, ou escolher seus livros; daqueles que não se deveria deixar a sós para enfrentar os perigos de certas leituras no universo cada vez mais amplo do texto escrito (p. 119).

Mas, como Michel de Certeau (1994) nos adverte, ler é uma operação de caça e haverá sempre táticas e astúcias, usadas pelo leitor, para burlar o que lhe é imposto como norma. 


\section{A leitura e seu controle: ler em silêncio, evitar as reticências}

\section{Cena 1}

São João Del Rei, Minas Gerais, meados do século XIX. Em uma das vilas mais urbanizadas do Brasil na época, homens das letras frequentavam sociedades literárias e gabinetes de leitura. Nesses espaços, lia-se em voz alta, trocavam-se ideias sobre as leituras realizadas, defendiam-se ardentemente opiniões relativas a assuntos de interesse público. Em espaços privados, mulheres liam, também em voz alta, folhetins, e as escravas domésticas e seus filhos, que não sabiam ler, ouviam atentamente a leitura ${ }^{11}$.

\section{Cena 2}

França, 1868. Em texto publicado no Bulletin de la Societé Franklin, Jean Macé demonstra sua preocupação com as "reticências" provocadas por leituras não acompanhadas, mesmo aquelas de obras "sérias" Para afastá-las, aconselhava os professores primários a abrir cursos para adultos em suas escolas e incluir no seu programa esse tipo de leitura (CHARTIER; HÉBRARD, 1995, p. 142).

\section{Cena 3}

Estamos agora em 2013, na biblioteca de uma famosa universidade do Meio-Oeste americano. Jovens, com notebooks e tablets nas mãos, conversam animadamente em salões claros, espaçosos, com pé direito alto. Blogs de leitores, sites que permitem o compartilhamento e download de artigos, de vídeos e de músicas, animam as conversas. Nos dez andares do edifício, há salas especificamente reservadas para aqueles que precisam do silêncio ${ }^{12}$.

A que essas diferentes cenas nos remetem? Desde o surgimento das primeiras bibliotecas, observamos, em diferentes momentos da história, uma tentativa de controlar não apenas as obras que deveriam ser lidas mas, também, o modo de ler. Muitas vezes, nessa história, há um aparente descompasso entre as práticas sociais de leitura e as práticas de leitura que deveriam ocorrer dentro da biblioteca. Como afirma Jean Hébrard (2009), a biblioteca representa um espaço territorializado do ler, ao contrário da colportagem e do gabinete de leitura: nela, o impresso torna-se um objeto controlado em sua produção e difusão. De modo diverso do que ocorre com o livro comprado ou emprestado em sociedades de leitura, o livro da biblioteca se impõe ao leitor em um espaço e em uma temporalidade que pouco lhe pertencem. Segundo o autor,

Toda apropriação concreta, real ou simbólica do objeto (conservação para releitura, comentário, anotação etc.) é

\footnotetext{
${ }^{11}$ Cena reconstruída a partir de Morais (2002).

${ }^{12}$ Cena reconstruída a partir de observações pessoais.
} 
proibida a quem empresta o livro e pode mesmo ser sancionada. Toda reciprocidade na troca - que se sabe é própria das sociedades de leitura, letradas ou não - choca-se com o anonimato do empréstimo e a necessária rotação das obras. Fazer do leitor, mesmo que já tenha saído do circuito da escolarização, um leitor acompanhado, tem-se aí o objetivo central da implantação das primeiras bibliotecas. (HÉBRARD, 2009, p. 16).

Assim, as sociabilidades em torno da leitura, tão comuns mesmo nos ambientes eruditos até o século XIX e que ressurgem com força nesse início do século XXI com as novas tecnologias, como mostram as cenas 1 e 3, precisavam/precisam ficar do lado de fora da biblioteca. Algumas poucas iniciativas têm conseguido acolher essas novas sociabilidades. Como já dizia o Regulamento da Biblioteca da Universidade de Paris, em vigor até, pelo menos, o século XV, na biblioteca, na maior parte das vezes, "que se escreva ou que se leia, não se deve interromper ninguém, seja conversando, seja andando" e, "tanto quanto possível, o silêncio deve reinar na biblioteca, como num lugar augusto e sagrado" (MARTINS, 2002, p. 91).

Ao mesmo tempo em que a leitura silenciosa viabilizaria de modo mais ordeiro o funcionamento das bibliotecas, havia também quem desconfiasse dessa relação entre leitor e livro, sem mediações, como mostra a cena 2 . Mesmo os livros sérios deveriam vir acompanhados de uma discussão liderada por um mediador autorizado, que impedisse que as reticências que ocorrem em qualquer leitura levassem a caminhos não previstos.

Evidentemente, nenhum controle é total. A história está repleta de exemplos de subversões tanto no que se lia quanto no como se lia. Ninguém nunca saberá (esperamos) o que o leitor faz com as reticências, principalmente se ele pode ler sozinho, em silêncio.

\section{O lugar do bibliotecário: guardião de livros ou mediador de leitura?}

Cena 1

França, 1839. São criadas as primeiras bibliotecas públicas que têm um caráter, predominantemente, de conservação. Alguns anos depois, essas instituições começaram a ser criticadas pelos "sérios danos" causados nos livros emprestados. Os "conservadores", formados pela Escola de Chartes, aprendem que, antes de mais nada, é preciso conservar e, consequentemente, desconfiar dos leitores, que muitas vezes são vistos como um obstáculo ao bom funcionamento da biblioteca. ${ }^{13}$

Cena 2

${ }^{13}$ Cena reconstruída a partir de Chartier e Hébrard (1995). 
Meados do século XIX, São João del Rei, Minas Gerais. Entre os funcionários do Gabinete Literário da cidade, o "Conservador", que também ocupava o cargo de bibliotecário da Livraria Pública, seria o responsável por manter a ordem, inventariar as "peças" do Gabinete e ajudar o "Redactor" em seus trabalhos ${ }^{14}$.

Cena 3

França. 1921. No Boletim da Associação dos Bibliotecários Franceses, afirma-se que: "Hoje, a biblioteca não deve continuar a ser um simples escritório de distribuição de livros, nem o bibliotecário, um funcionário incumbido do material impresso, que registra as entradas e saídas de livros, [mas sim] um professor de leitura". (COYECQUE IN BULLETIN ABF, 1921, p. 12 apud CHARTIER; HÉBRARD, 1995, p. 163).

Como mostram as cenas 1 e 2, até o século XIX, mesmo depois do surgimento das primeiras bibliotecas públicas, o bibliotecário é, prioritariamente, um guardião dos livros. Cabe a ele não somente evitar que se estraguem mas, também, identificá-los, ordená-los, classificá-los. Depoimentos sobre extravios de obras, os perigos do empréstimo, o melhor modo de conservá-las, o que deve ser evitado para que o leitor a estrague são constantes em diferentes espaços sociais, no período.

A partir do século XX, como mostra a cena 3, esse papel começa a, paulatinamente, mudar. Novas demandas são postas para os bibliotecários. Começam a se proliferar argumentos de que as bibliotecas existem para o público e a conservação só faz sentido em função do uso: "Em conseqüência, o bibliotecário não é nem deve ser um sábio que põe os livros a serviço dos seus próprios trabalhos". (CHARTIER; HÉBRARD, 1995, p. 150).

O bibliotecário passa a ser visto como um profissional que tem que conjugar o conhecimento técnico, a cultura geral (ou especializada, no caso da biblioteca especializada) e, de preferência, o conhecimento dos leitores (CHARTIER; HÉBRARD, 1995, p. 151). Tarefa impossível?

$\mathrm{E}$, nos anos 1950, diante dos novos inimigos da biblioteca, o cinema, o rádio e a televisão, e dos antigos, os romances, a tarefa mais importante do bibliotecário continuava a ser a de orientar o leitor com respeito a esse tipo de literatura. Como esse gênero representava $80 \%$ de todos os empréstimos, merecia a vigilância mais cuidadosa (CHARTIER; HÉBRARD, 1995, p. 193).

Mas, sem dúvida, no século $X X$, há uma gradativa substituição da hierarquização entre boas e más leituras e a condenação explícita dessas últimas, para uma concepção mais flexível. Essa transformação, por sua vez, deixou (tem deixado?) muito menos nítida a tarefa do bibliotecário (CHARTIER; HÉBRARD, 1995).

\section{Considerações finais}

\footnotetext{
${ }^{14}$ Cena reconstruída a partir de Morais (2002).
} 
Os tempos mudaram, as inquietações e ameaças que rondam a biblioteca se transformaram. Mas, a história nos faz pensar sobre a permanência de algumas delas, que continuam a nos atormentar, em relação ao acesso e ao público, ao acervo, ao controle da leitura e ao papel do bibliotecário.

Como expandir as bibliotecas até os lugares mais remotos? Como compreender a sua ausência em lugares tão óbvios, como instituições públicas de educação infantil (PEREIRA, 2011)? Como torná-la atraente a um público cada vez mais amplo e com interesses tão diversos? Como dissociá-la da imagem do medo, do silêncio e do sagrado? Como associála a um lugar de prazer? Como acolher os neo-leitores, crianças e adultos que, em um país de universalização tardia da escolarização, como o Brasil, começam, nesse início do século XXI, a procurar livros, livrarias e bibliotecas? Como fazer compreender que sempre haverá ameaças aparentes à biblioteca?

Como se desvencilhar de uma concepção iluminista de leitura, que atribui ao livro o poder de mudar as mentes? Como, então, libertar-se da ideia de que o neo-leitor é incapaz de construir sua própria trajetória de leitor e insistir em prescrever-lhe o que deve e o que não deve ser lido? Como incorporar a discussão da ideia, na formação de professores e de bibliotecários, de que as boas e as más leituras são uma construção histórico-social e que os cânones literários não são absolutos nem universais?

Muitas perguntas. Poucas respostas. Apenas uma certeza - se é que há alguma espécie de certeza quando falamos na perspectiva da História: livros sempre circularam, sempre foram lidos, apesar da escola, apesar da biblioteca.

\section{Referências}

CARNEIRO, Maria Luiza Tucci. Livros proibidos, ideias malditas. São Paulo: Ateliê Editorial, 2002.

CERTEAU, Michel de. A escrita da história. Rio de Janeiro: Forense Universitária, 1982.

CERTEAU, Michel de. A invenção do cotidiano: artes de fazer. Petrópolis: Vozes, 1994.

CHARTIER, Anne-Marie; HÉBRARD, Jean. Discursos sobre a leitura (18801980). São Paulo: Ática, 1995.

COSTA, Lúcia de Fátima Vieira da; GERMANO, José Willington. Anos 60: leitura e educação popular no discurso dos inquisidores. In: CONGRESSO BRASILEIRO DE HISTÓRIA DA EDUCAÇÃO, 3., 2002, Anais... Natal, 2002. Disponível em: <http://www.sbhe.org.br/novo/congressos/cbhe2/pdfs/Tema2/0202.pdf. $>$. Acesso em: 15 mar. 2013. 
DAMON-MOORE, Helen; KAESTLE, Carl F. Surveying American readers. In: KAESTLE, Carl F. (Ed.). Literacy in the United States: readers and reading since 1880. New Haven: Yale University Press, 1991. p. 180-203.

GALVÃO, Ana Maria de Oliveira. Autobiografias e novos letrados: um estudo comparativo (Illinois, Estados Unidos; Minas Gerais, Brasil, primeira metade do século $X X)$. Relatório de Pesquisa. Dekalb, Illinois: Northern Illinois University, 2013.

GALVÃO, Ana Maria de Oliveira. Cordel: leitores e ouvintes. Belo Horizonte: Autêntica, 2001.

HÉBRARD, Jean. As bibliotecas escolares: entre leitura pública e leitura escolar na França do II Império e III República. Campinas: Mercado de Letras, 2009.

INSTITUTO BRASILEIRO DE GEOGRAFIA E ESTATÍSTICA IBGE. Enciclopédia dos municípios brasileiros. Separata do volume 24. Editada em homenagem ao $60^{\circ}$ aniversário de Belo Horizonte. Rio de Janeiro, 1957.

KAESTLE, Carl F. (Ed.). Literacy in the United States: readers and reading since 1880. New Haven: Yale University Press, 1991.

MARTINS, Wilson. A palavra escrita: história do livro, da imprensa e da biblioteca. 3. ed. São Paulo: Ática, 2002.

MINAS GERAIS. Ofícios da Diretoria Geral de Instrução Pública (18691870). Códice: 1340 - 05/01/1870. Arquivo Público Mineiro, 1934.

MORAES, Rubem Borba de. Livros e bibliotecas no Brasil colonial. 2. ed. Brasília: Briquet de Lemos, 2006.

MORAIS, Christiani Cardoso. Para aumento da instrução da mocidade da nossa pátria: estratégias de difusão do letramento na Vila de São João Del-Rei (1824-1831). Dissertação (Mestrado em Educação)-Universidade Federal de Minas Gerais, Belo Horizonte, 2002.

PEREIRA, Fernanda Rohlfs. A literatura infantil na UMEIs de Belo Horizonte: literatura distribuída, literatura incluída?. Monografia (Conclusão do curso de Pedagogia)-Faculdade de Educação, Universidade Federal de Minas Gerais, Belo Horizonte: 2011.

PERES, Eliane Teresinha. "Templo de Iuz": os cursos noturnos masculinos de instrução primária da Biblioteca Pública Pelotense (1875-1915). Pelotas: Seiva Publicações, 2002.

PETRUCCI, Armando. Alfabetismo, escritura y sociedad. Barcelona: Gedisa Editorial, 1999.

PRIMEIRA visitação do Santo Ofício às partes do Brasil: denunciações e confissões de Pernambuco, 1593-1595. Recife: Fundarpe, Diretoria de Assuntos Culturais, 1984 [edição fac-símile]. 
SANTOS, Maria José Lima dos. Entre comportamento permitido e leitura proibida: Paula de Siqueira, uma leitora de Diana. Revista Fórum Identidades, Ano 1, v. 2, p. 68-73, 2007.

SCHWARCZ, Lilia Moritz; COSTA, Paulo César de Azevedo. A longa viagem da biblioteca dos reis: do terremoto de Lisboa à Independência do Brasil. São Paulo: Companhia das Letras, 2002.

TINSLEY, Katherine; KAESTLE, Carl. Autobiographies and the History of Reading: the meaning of literacy in individual lives. In: KAESTLE, Carl F. (Ed.). Literacy in the United States: readers and reading since 1880 . New Haven: Yale University Press, 1991. p. 225-244.

VERRI, Gilda Maria Whitaker. Templários da ausência em bibliotecas populares. Recife: Ed. UFPE, 1996.

VIDAL, Diana Gonçalves. Uma biblioteca escolar: práticas de formação docente no Rio de Janeiro, 1927-1935. In: CARVALHO, Marta Maria Chagas de; VIDAL, Diana Gonçalves (Org.). Biblioteca e formação docente: percursos de leitura. Belo Horizonte: Autêntica, 2000, p. 11-36.

VILLALTA, Luiz Carlos. O que se fala e o que se lê: língua, instrução e leitura. In: SOUZA, Laura de Mello e (Org.). História da vida privada no Brasil: cotidiano e vida privada na América Portuguesa. São Paulo: Companhia das Letras, 1997. p. 331-385. 